\title{
INTERVENSI KOMUNITAS: STRATEGI PENANGGULANGAN BENCANA BERBASIS MASYARAKAT DI KABUPATEN DELI SERDANG
}

\author{
Ahmad Yaneri \\ Politeknik Kesejahteraan Sosial Bandung \\ Email: ahmadyaneri@gmail.com
}

\begin{abstract}
Abstrak
Laporan tahunan BPBD Sumatera Utara menunjukkan hampir setiap tahun di beberapa titik wilayah mengalami peningkatan bencana alam, hal ini berimplikasi pada pembentukan Taruna Siaga Bencana (Tagana) di Kabupaten Deli Serdang. Melalui pendekatan kualitatif, penelitian ini mendeskripsikan bagaimana intervensi komunitas yang dilakukan oleh Tagana di Kabupaten Deli Serdang dalam fase penanggulangan bencana alam yang medorong partisipasi masyarakat lokal agar menciptakan kemandirian dalam menyelesaikan masalah terutama kesiapsiagaan dalam menghadapi bencana alam. Hasil temuan di lapangan, pelaksanaan intervensi komunitas oleh Tagana dalam penanggulangan bencana alam sudah maksimal karena adanya beberapa faktor pendukung seperti partisipasi masyarakat dan tenaga profesional dalam hal kebencanaan. Tidak terlepas dari itu, Tagana juga menghadapi faktor penghambat dalam pelaksanaan intervensi komunitas seperti predisposisi dan ketergantungan masalah dana.
\end{abstract}

Kata Kunci: Intervensi Komunitas, Penanggulangan Bencana, Tagana.

\section{Abstract}

The BPBD annual report of North Sumatera shows that almost every year at several points the area has experienced an increase in natural disasters, this has implications for the formation of disaster preparedness cadets (Tagana) in Deli Serdang Regency who act as the front guard in disaster management. Through a qualitative approach, this thesis was conducted to describe how community intervention applied by Tagana in Deli Serdang regency in managing natural disaster so that it creates self-community in solving the problems, particularly the alertness in preparation to face natural disaster. The research findings show that, implementation of community interventions by Tagana in disaster management in Deli Serdang has a maximum are because of several supporting factors such as the community participation and professional personnel in terms of disaster expertise. In addition, Tagana is also facing the obstacle factors in the implementation of community interventions such as the predisposition and the dependence on funding.

Keywords: Community Intervention, Disaster Management, Tagana.

\section{A. PENDAHULUAN}

Bencana alam adalah masalah global yang terjadi di seluruh dunia (Alcántara-Ayala, 2002). Meskipun mereka mungkin memiliki dampak yang cukup besar di negara-negara seperti Jepang, AS, Prancis atau Swiss, signifikansinya di negara-negara seperti Bangladesh, India, Cina, Guate-mala, Kolombia atau Meksiko jauh lebih besar (Toya \& Skidmore, 
2007). Jumlah kematian global akibat bencana alam terkonsentrasi di negara berkembang (juga disebut Negara Dunia Ketiga), dan bisa mencapai 95\% dari total korban (Strobol, 2012).

Sebagian besar negara berkembang terletak di daerah yang sangat rawan bencana alam. Vulkanisme dikaitkan dengan area tertentu seperti Circum-Pacific Volcanic Belt, di mana sekitar $80 \%$ dari total aktivitas terjadi (Ferrier \& Spickett, 2007). Banyak negara Amerika Latin dan Asia terletak di daerah ini, dan efek vulkanisme dan risiko yang terkait dapat menyebabkan populasi yang tinggal di dekat diamati dalam bencana seperti bencana Nevado del Ruiz di Kolombia dimana 21.800 orang tewas (Caruso, 2017).

Asia dan Amerika Latin berbagi konsentrasi banjir tertinggi dan risiko terkait akibat angina puyuh, siklon, badai tropis, topan, dan mon-soon (Benson \& Clay, 2000). Menurut bencana alam yang terjadi antara tahun 1900 dan 1999, 42\% dari jumlah total terjadi di Asia, sedangkan Amerika memiliki 27\%, Eropa 13\% dan Oseania dan Afrika, 8\% dan 10\%. Distribusi spasial bencana alam menunjukkan kecenderungan yang jelas terjadi di negara berkembang (Crespo Cuaresma dkk, 2008). Selain itu, dampaknya tercermin mengingat biaya yang ditimbulkan akibat terkait dengan GNP, PDB, dan waktu yang dibutuhkan untuk pemulihan sebagian atau total. Misalnya, lebih dari 9000 orang kehilangan nyawa dan sekitar 11\% (3,2 juta orang) dari total penduduk di Amerika Tengah terkena dampak dari Badai Mitch. Dampaknya tidak homogen di semua negara. Di Honduras kerugian itu setara dengan $80 \%$ dari PDB 1997, sedangkan di Nikaragua hampir $49 \%$ dari PDB (Delaney \& Shrader, 2000; Davis, 2017). Total kerugian dari seluruh wilayah diperkirakan mencapai US \$ 6 miliar memiliki konsentrasi kerusakan langsung yang sedikit lebih besar $(51,5 \%)$ dari pada kerusakan tidak langsung (48,5\%). Lebih lanjut, kerusakan penduduk hampir tidak dapat dievaluasi secara finansial dan dalam kaitannya dengan waktu pemulihan pasca bencana (Roper, 2001).

Terjadinya bencana alam di Indonesia tidak lepas dari letak geografis Indonesia yang rentan terhadap musibah bencana alam (Hidayati, 2008). Indonesia terletak di ring of fire secara geografis yang menyebabkan Indonesia rawan terjadi bencana alam (Tondobala, 2012). Sementara itu berdasarkan penelitian dari tim ITB (2009) dinyatakan bahwa setiap tahun Indonesia berpotensi mengalami bencana alam yang berdampak bagi kehidupan manusia. Sebaran kejadian bencana alam di wilayah Indonesia pun beragam, tergantung dari letak geografis dan struktur alamnya (Sadisun, 2004). Tabel dibawah ini merangkum 
informasi dari Badan Nasional Penanggulang Bencana (BNPB) mengenai jumlah kejadian bencana yang terjadi di beberapa provinsi di Indonesia.

Tabel 1 Sebaran Jumlah Kejadian Bencana di Provinsi Indonesia pada Tahun 2013

\begin{tabular}{|c|l|c|c|l|c|}
\hline No & Nama Provinsi & $\begin{array}{c}\text { Jumlah } \\
\text { Kejadian }\end{array}$ & No & Nama Provinsi & $\begin{array}{c}\text { Jumlah } \\
\text { Kejadian }\end{array}$ \\
\hline 1 & Aceh & 746 & 18 & Nusa Tenggara Barat & 283 \\
\hline 2 & Sumatera Utara & 539 & 19 & Nusa Tenggara Timur & 526 \\
\hline 3 & Sumatera Barat & 489 & 20 & Kalimantan Barat & 160 \\
\hline 4 & Riau & 176 & 21 & Kalimantan Tengah & 129 \\
\hline 5 & Kepulauan Riau & 52 & 22 & Kalimantan Selatan & 641 \\
\hline 6 & Jambi & 270 & 23 & Kalimantan Timur & 580 \\
\hline 7 & Sumatera Selatan & 547 & 24 & Kalimantan Utara & 2 \\
\hline 8 & Bengkulu & 89 & 25 & Sulawesi Utara & 167 \\
\hline 9 & Lampung & 346 & 26 & Sulawesi Tengah & 208 \\
\hline 10 & Bangka Belitung & 10 & 27 & Sulawesi Selatan & 679 \\
\hline 11 & DKI Jakarta & 297 & 28 & Sulawesi Tenggara & 596 \\
\hline 12 & Banten & 290 & 29 & Sulawesi Barat & 93 \\
\hline 13 & Jawa Barat & 2.070 & 30 & Gorontalo & 107 \\
\hline 14 & Jawa Tengah & 3.149 & 31 & Maluku & 144 \\
\hline 15 & D.I. Yogyakarta & 216 & 32 & Maluku Utara & 62 \\
\hline 16 & Jawa Timur & 1.572 & 33 & Papua Barat & 19 \\
\hline 17 & Bali & 259 & 34 & Papua & 109 \\
\hline
\end{tabular}

Sumber: Data Badan Nasional Penanggulangan Bencana, 2013.

Berdasarkan data tabel di atas, jumlah kejadian bencana cukup tinggi hamper diseluruh provinsi yang ada di Indonesia sehingga jelas bahwa bencana alam merupakan masalah serius yang harus disikapi dengan berbagai penanggulangan bencana yang strategis dan efektif, tercatat prevalensi kejadian bencana alam di kota-kota besar di Indonesia mencapai angka ribuan seperti pada Provinsi Jawa Tengah yaitu pada angka 3.149. Kejadian bencana pasti akan menelan korban jiwa maupun materi, sehingga dampak dari bencana alam tersebut dapat diminimalisir, dalam hal ini masalah korban jiwa khususnya. Hal ini sebagaimana yang dikemukakan oleh Nurjanah (2012), bahwa setiap bencana alam akan selalu menelan berbagai korban, baik korban jiwa, materi, sosial dan fisik. Aspek-aspek yang berbeda ini menanggapi bencana alam pada berbagai tahapan (yaitu tahap pra-bencana, pasca bencana dan pasca bencana) (Widianto, 2019).

Salah satu komponen dalam melakukan manajemen bencana khususnya dalam pengelolaan sumber daya manusia pada lokasi bencana adalah relawan sosial (Christy \& Sahrani, 2017). Dimana maksud dari relawan sosial ini sebagaimana yang dijelaskan dalam UU Nomor 11 tahun 2009 tentang Kesejahteraan Sosial pasal 1 ayat 5, yakni seseorang dan/atau kelompok masyarakat, baik yang berlatar belakang pekerjaan sosial maupun bukan 
berlatar belakang pekerjaan sosial, tetapi melaksanakan kegiatan penyelenggaraan di bidang sosial bukan di instansi sosial pemerintah atas kehendak sendiri dengan atau tanpa imbalan. Salah satu relawan sosial yang dapat membantu dalam manajemen kebencanaan yaitu Taruna Siaga Bencana atau disingkat TAGANA.

Peran TAGANA sebagai satuan tugas penanggulangan bencana yang berbasis masyarakat dituntut untuk terus dapat meningkatkan potensi dirinya dalam bidang kebencanaan (Wulandari, 2017). Peningkatan ini tidak hanya tercermin dari jumlah partisipasi TAGANA dalam kegiatan penanggulangan bencana, tetapi juga kualitas kemampuannya dalam menerapkan prinsip-prinsip penanggulangan bencana (Syamsuddin, 2019). Selain UU Nomor 24 tahun 2007, TAGANA juga diamanatkan dalam Peraturan Menteri Sosial Nomor 28 Tahun 2012 Tentang Pedoman Umum Taruna Siaga Bencana. Dimana dalam Pasal 1 ayat 1 pada Peraturan Menteri Sosial tersebut disebutkan bahwa Taruna Siaga Bencana selanjutnya disingkat TAGANA adalah relawan sosial atau Tenaga Kesejahteraan Sosial berasal dari masyarakat yang memiliki kepedulian dan aktif dalam penanggulangan bencana bidang perlindungan sosial. Dengan demikian keberadaan TAGANA merupakan komponen penanggulangan bencana yang legal dan diatur dalam peraturan konstitusi.

Dari semua daerah di Indonesia, salah satu daerah yang memiliki tim TAGANA adalah Kabupaten Deli Serdang, Sumatera Utara. Kondisi geografis Kabupaten Deli Serdang rentan terjadinya gempa bumi, menyempitnya lahan serapan air akibat meningkatnya kebutuhan lahan untuk sektor bisnis dan permukiman membuat bencana alam di Deli Serdang semakin potensial terjadi. Apalagi gunung berapi Sinabung yang lokasinya di Kabupaten Karo, Sumatera Utara letaknya tidak terlalu jauh dengan Kabupaten Deli Serdang, sehingga saat gunung tersebut memuntahkan debu vulkaniknya, maka tidak tertutup kemungkinan muntahan debu vulkanik tersebut dapat menjangkau ke seluruh wilayah Kabupaten Deli Serdang. Mengingat tingginya tingkat bahaya yang dihasilkan oleh bencana, maka untuk itulah peran TAGANA dalam membantu masyarakat yang rentan menjadi korban bencana alam sangat penting intervensi komunitasnya. Apalagi mengingat BPBD Kabupaten Deli Serdang belum terbentuk. Sehingga dengan adanya TAGANA Kabupaten Deli Serdang sangat membantu peran dan fungsi BPBD Provinsi Sumatera Utara dalam penanggulangan bencana di Kabupaten Deli Serdang. 


\section{B. METODE}

Pendekatan Kualitatif digunakan dalam penelitian ini. Sementara untuk jenis penelitian ini adalah penelitian deskriptif. Menurut Rubin \& Babbie (2008), "penelitian deskriptif kualitatif berkaitan dengan penyampaian terhadap individu untuk dijelaskan, memberikan gambaran tentang lingkungan mereka yang lebih detail, interaksi, makna dan kehidupan sehari-hari”.

Penelitian ini mengambil lokasi di 3 kecamatan di Kabupaten Deli Serdang, Sumatera Utara, yaitu Kecamatan Galang, Kecamatan Hamparan Perak, dan Kecamatan Sibolangit. Lamanya penelitian ini yaitu 21 bulan, yaitu dari bulan Oktober 2013 sampai bulan Juli 2015. Untuk informan dalam penelitian ini yaitu Anggota dan Pengurus TAGANA Kabupaten Deli Serdang, Pengurus Kecamatan Galang, Pengurus RT. 06 di Klambir Lima Kebon, Kecamatan Hamparan Perak, dan Pengurus RW 04 di Kelurahan Bingkawan, Kecamatan Sibolangit. Pengumpulan data primer dilakukan dengan observasi dan wawancara sedangkan data sekunder di ambil dari literatur yang berhubungan dengan penelitian.

\section{HASIL DAN PEMBAHASAN}

\section{Pelaksanaan Intervensi Komunitas Oleh TAGANA Dalam Masalah Bencana Alam di Kabupaten Deli Serdang, Sumatera Utara}

Bencana alam yang terjadi di Kabupaten Deli Serdang dipengaruhi oleh berbagai faktor, baik itu karena kondisi alam maupun aktivitas manusia itu sendiri. Ada pun para pemangku yang terkait dengan penanggulangan bencana di Kabupaten Deli Serdang yaitu: (a) Badan Penanggulangan Bencana Daerah Provinsi Sumatera Utara; (b) Dinas Sosial Kabupaten Deli Serdang; (c) PMI (Palang Merah Indonesia) Daerah Kabupaten Deli Serdang; (d) BASARNAS (Badan Sar Nasional) Kabupaten Deli Serdang; (e) TAGANA (Taruna Siaga Bencana); (f) Lembaga Swadaya Masyarakat (LSM); dan (g) Organisasi Masyarakat (Ormas).

Terkait dengan penjelasan singkat di atas, dalam kegiatan penanggulangan bencana posisi BPBD Provinsi Sumatera Utara menjadi lembaga utama yang melakukan berbagai komando dan kordinasi kepada pihak-pihak yang terlibat dalam kegiatan penanggulang bencana di Provinsi Sumatera Utara dan khususnya di Kabupaten Deli Serdang. Namun dalam melaksanakan kegiatannya, BPBD Provinsi Sumatera Utara tentu perlu bekerjasama dengan berbagai pihak. Hal ini untuk memaksimalkan kegiatan penanggulangan bencana. Namun sangat disayangkan BPBD Kabupaten Deli Serdang belum terbentuk. Dalam konteks 
di Kabupeten Deli Serdang, BPBD Provinsi Sumatera Utara bekerjasama dan berkoordinasi dengan Dinas Sosial Kabupeten Deli Serdang termasuk TAGANA. Dengan kata lain, dalam posisi penanggulangan bencana TAGANA menjadi elemen yang membantu fungsi BPBD Provinsi Sumatera Utara dalam penanggulangan bencana di Kabupeten Deli Serdang. Karena belum dibentuknya BPBD Kabupaten Deli Serdang itulah yang membuat pemerintah daerah melalui Dinas Sosial membentuk TAGANA. Selain itu untuk memperkuat pengetahuan dan keterampilan dalam penanggulangan bencana, Dinas Sosial Kabupaten Deli Serdang bekerjasama dan berkordinasi dengan BPBD Provinsi Sumatera Utara. Selain itu juga dengan terbentuknya TAGANA Kabupaten Deli Serdang, ini tentu membantu BPBD Provinsi Sumatera Utara dalam melakukan kegiatan penanggulangan bencana di daerah Kabupaten Deli Serdang.

Masalah bencana menjadi permasalahan kesejahteraan sosial, dan berdampak pada terhambatnya proses pembangunan sosial. Dimana dampak bencana tentu membuat aktivitas individu, masyarakat dan pemerintah mengalami gangguan dan hambatan (Tselios \& Tompkins, 2019). Midgley (2005), mengungkapkan, strategi pembangunan sosial dapat diterapkan melalui komunitas, dan kelompok komunitas bekerja sama untuk mengembangkan komunitas lokalnya. Untuk itu dalam upaya penanggulangan bencana strategi pembangunan sosial dalam bentuk intervensi komunitas perlu diterapkan untuk meningkatkan kesiapsiagaan masyarakat ketika bencana datang.

Mengacu penjelasan di atas, dengan adanya bencana jelas akan menghambat proses pembangunan sosial. Mengingat dampak bencana bersifat efek domino, dari dampak sosial, kesehatan sampai kemudian berdampak ekonomi. Oleh karena itu untuk meningkatkan kesiapsiagaan masyarakat Kabupaten Deli Serdang sebelum atau saat bencana datang maka dibentuklah TAGANA yang di fasilitasi oleh Dinas Sosial Kabupaten Deli Serdang bekerjasama dengan Dinas Sosial Provinsi Sumatera Utara. Maka dalam hal ini peneliti bermaksud menguraikan pembahasan mengenai pelaksanaan model intervensi komunitas pada penanggulangan bencana oleh TAGANA di Kabupaten Deli Serdang.

Berdasarkan temuan lapangan, hasil analisis dari pelaksanaan program intervensi komunitas oleh TAGANA berdasarkan penelitian Rothman dan Tropman dengan model intervensi komunitas yaitu, pengembangan masyarakat lokal (Model A) dengan mengambil 9 unsur dari 12 unsur yang dikemukakan (Adi, 2008). Penjelasan tentang pelaksanaan model intervensi komunitas oleh TAGANA sebagai berikut: 
a. Kategori tujuan tindakan terhadap masyarakat

Berdasarkan temuan lapangan, untuk kategori tujuan tindakan terhadap masyarakat dengan terbentuknya TAGANA di Kabupaten Deli Serdang diharapkan mampu menciptakan kemandirian, pengembangan kapasitas dan pengintegrasian masyarakat dalam menyelesaikan masalah mengenai bencana (Model A). Dari kategori tujuan tersebut TAGANA tidak termasuk dalam perencanaan sosial maupun aksi sosial. Walaupun terwujudnya kemandirian masyarakat dalam penanggulangan bencana, namun masyarakat tetap membutuhkan TAGANA dalam menjalankan program-program kebencanaan.

b. Asumsi mengenai struktur komunitas dan kondisi permasalahan

Dalam rangka upaya penanggulangan bencana di Kabupaten Deli Serdang tidak lepas dari aktifitas dalam memberdayakan masyarakatnya untuk mengantisipasi pengurangan risiko bencana. Untuk itulah diperlukan kesadaran masyarakat dalam hal mengantisipasi dampak yang terjadi yang diakibatkan oleh bencana. Adapun struktur komunitas yang ada berkaitan dengan lingkup geografis atau wilayah yang selalu mengalami bencana setiap tahunnya, sehingga struktur komunitas dan kondisi permasalahan yang terjadi menjadi salah satu dasar bagi pemerintah setempat untuk melakukan kebijakan dalam bentuk intervensi di bidang kebencanaan. Apalagi permasalahan bencana merupakan permasalahan yang kompleks pada setiap negara, salah satunya Indonesia dan terkhusus di Deli Serdang, Sumatera Utara.

c. Strategi dasar dalam melakukan perubahan

Secara strategi TAGANA sudah menjalankan fungsinya dengan baik. Panduan kesiapsiagaan bencana menyatakan bahwa TAGANA berperan dan berfungsi bagi masyarakat sebagai penyuluh, motivator dan pembina yang mementori masyarakat sekitar dalam aktifitas dan upaya kesiapsiagaan bencana di wilayahnya. Apa yang dilakukan oleh TAGANA dalam penanggulang bencana alam di Kabupaten Deli Serdang, setidaknya sudah sesuai dengan Undang-Undang Nomor 24 Tahun 2007 pada pasal 4.

Berdasarkan temuan data di lapangan, TAGANA menjalankan perannya tersebut dengan baik. Hal ini terlihat dari pelatihan, simulasi serta sosialisasi yang dilakukanketika kegiatan saat dan pasca bencana. Untuk mendukung dalam upaya penanggulangan permasalahan bencana di Kabupaten Deli Serdang melibatkan masyarakat dalam membuat jalur evakuasi dan peta rawan bencana untuk masyarakat. Pembuatan jalur evakuasi dan peta bencana disusun untuk memberikan gambaran ke masyarakat tentang wilayah mana yang rawan bencana dan untuk pedoman bagi para anggota TAGANA dalam upaya evakuasi di masyarakat. Selain itu tujuan dari pembuatan jalur evakuasi dan peta rawan bencana 
bertujuan agar masyarakat mendapatkan informasi yang dibutuhkan dalam penanggulangan bencana.

d. Karakteristik taktik dan teknik perubahan

Untuk memaksimalkan kegiatan intervensi, berbagai taktik dan teknik perubahan pun dilakukan oleh TAGANA. Dimana TAGANA selalu memberikan kegiatan pelatihan kepada masyarakat maupun kepada para calon relawan TAGANA. Dalam pemberian proses kegiatan, para peserta mengikuti pelaksanaan pelatihan yang diberikan oleh fasilitator, selanjutnya dilakukan pre-test untuk mengukur sejauh mana pemahaman awal serta pengetahuan peserta dalam kebencanaan. Setelah itu dilaksanakan diskusi dan praktek, penyampaian materi dalam suasana santai dan serius. Direkomendasikan agar peserta segera mengajukan pertanyaan, argumen atau tambahan, tetapi tetap harus melanjutkan di bawah bimbingan tuan rumah.

Selain itu juga, TAGANA dalam menjalankan perannya sudah sesuai taktik dan teknik perubahan dengan penanggulangan bencana pada umumnya. Dalam hal ini seperti apa yang dikemukakan oleh Sunarti (2009), mengenai penanggulangan bencana yang terbagi menjadi tiga kondisi, yaitu: kondisi pra bencana, kondisi saat bencana, dan kondisi pasca bencana.

e. Peran praktisi yang menonjol

Dalam menjalankan kegiatannya, TAGANA dibantu oleh para praktisi dibidang kebencanaan. Dimana para praktisi tersebut memberikan pengetahuan dan keterampilan kepada para anggota TAGANA dan juga masyarakat. Para praktisi itu ada yang berasal dari Dinas Sosial Kabupaten Deli Serdang, Dinas Sosial Propinsi Sumatera Utara.

Kehadiran para praktisi dalam kegiatan ini menjadi salah satu kunci keberhasilan kegiatan intervensi terhadap masalah kebencanaan. Hal ini seperti yang dikemukakan oleh Midgley (2005). bahwa program pembangunan masyarakat bergantung pada tenaga profesional yang terlatih untuk menggerakkan masyarakat lokal, Mengatur kegiatan, dan menjembatani dengan pihak eksternal. Para profesional bisa dari badan pengembangan masyarakat yang dipekerjakan dan bisa juga menggunakan tenaga lokal yang sudah terlatih.

f. Orientasi terhadap struktur kekuasaan

TAGANA sebagai organisasi yang membantu pemerintah daerah dalam hal ini Kabupaten Deli Serdang dibentuk dan dibina oleh Kementerian Sosial RI yang mempunyai struktur organisasi dibawah naungan dinas sosial. Struktur TAGANA dibuat sesuai kebutuhan. Peran ketua berkoordinasi dengan anggotanya dalam hal sosialisasi, 
mempersiapkan tugas-tugas apa yang harus dilakukan ketika bencana datang dan juga berkoordinasi langsung dengan ketua RW maupun ketua RT setempat. TAGANA membentuk kepengurusan sesuai dengan kebutuhannya. Dalam hal ini tampak ketika TAGANA menginternalisasikan nilai-nilai dalam tindakannya guna menanggulangi bencana.

g. Batasan definisi penerima layanan

Berdasarkan temuan lapangan, TAGANA mengikutsertakan setiap kesatuan yang ada dalam masyarakat sehinggga semua merasa peduli dan saling memiliki. Dimana masyarakat sasaran dalam kegiatan intervensi kebencanaan adalah yang berdomisili di daerah rawan bencana di Kabupaten Deli Serdang. Midgley (2005), mengungkapkan bahwa program pemberdayaan masyarakat tergantung letak geografisnya. Lingkup dan fokusnya lebih bersifat lokal pada lingkungan masyarakat tertentu. Dengan kata lain, program harus di sesuaikan dengan kondisi geografis masyarakatnya. Hal tersebut juga sesuai yang diungkapkan oleh Rothman dalam pengembangan masyarakat lokal (Model A) yaitu keseluruhan komunitas geografis (Adi, 2008).

h. Konsepsi mengenai peran penerima layanan

Dalam upaya memberikan intervensi mengenai kebencanaan, TAGANA berharap dari berbagai kegiatan sosialisasi maupun pelatihan yang sudah dilakukan dapat mendorong peran masyarakat untuk berpartisipasi dalam masalah kebencanaan di wilayahnya masing-masing. Partisipasi perlu dukungan dari masyarakat. Masyarakat punya andil besar dalam upaya pengurangan risiko bencana, tanpa adanya masyarakat yang berpartisipasi dalam kegiatan kebencanaan, maka peran TAGANA tidak akan maksimal.

Berdasarkan temuan lapangan tersebut jika dikaitkan dengan yang diungkapkan oleh Rothman bahwa komunitas berusaha belajar dan mengembangkan diri untuk menyelesaikan masalahnya (Model A), dan tidak seperti kebijakan/perencanaan sosial hanya sebagai konsumen (Model B) maupun aksi sosial yang hanya sebagai korban dari sistem (Model C) (Adi, 2008). Karena di dalam pelaksanaan program, TAGANA melibatkan warga ikut berperan dalam proses penentuan tujuan dan kebijakan. Sejalan dengan pendapat Hikmat (2004), bahwa tujuan dari intervensi pada komunitas yaitu meningkatkan potensi yang ada dalam diri masyarakat melalui perantara pihak tertentu dalam rangka mewujudkan keberdayaan masyarakat pada level kesejahteraan sosialnya.

i. Pemanfaatan pemberdayaan

Kegiatan pemberdayaan yang dilakukan oleh TAGANA kepada masyarakat dimanfaatkan untuk mengembangkan kapasitas masyarakat untuk mengambil keputusan 
bersama serta membangkitkan rasa percaya diri akan kemampuan masing-masing anggota masyarakat dalam menghadapi bencana alam yang terjadi dan akan datang. Hal ini seperti apa yang dikemukakan oleh Loekman (1995) bahwa intervensi pada masyarakat menjadi satu bentuk kegiatan untuk mewujudkan masyarakat yang partisipatif pada setiap kebijakan dan program yang ada.

TAGANA melakukan pemberdayaan seperti apa yang dikemukakan oleh Rothman, yaitu melakukan pengembangan masyarakat lokal (locality developmen) (Adi, 2008). Sebab dalam kegiatan yang dilakukan oleh TAGANA berkaitan dengan mengembangkan pengetahuan dan keterampilan masyarakat mengenai bencana dan penanggulangan bencana. Dimana sebelumnya masyarakat masih minim atau rendah pengetahuan dan keterampilannya mengenai bencana dan penanggulangan bencana.

\section{Faktor Pendukung dan Penghambat Pelaksanaan Intervensi Komunitas oleh TAGANA dalam Penanggulangan Bencana Alam}

Berdasarkan temuan di lapangan, maka faktor pendukung yang dapat membantu keberhasilan pelaksanaan model intervensi komunitas TAGANA dalam penanggulangan bencana alam di Kabupaten Deli Serdang, yaitu sebagai berikut:

a. Adanya partisipasi masyarakat

Dengan adanya intervensi yang dilakukan oleh TAGANA, diharapkan dapat meningkatkan partisipasi masyarakat pada permasalahan kebencanaan. Seperti yang dikatakan Glen (Adi, 2008), dari perspektif keberadaan atau perkembangan partisipasi masyarakat, hakikat kesejahteraan dalam wacana ini. Partisipasi masyarakat dalam proses pemberdayaan masyarakat merupakan salah satu kunci terciptanya kesejahteraan masyarakat. Oleh karena itu menurut Hikmat, tujuan dari intervensi yaitu meningkatkan potensi yang ada dalam diri masyarakat melalui perantara pihak tertentu dalam rangka mewujudkan keberdayaan masyarakat pada level kesejahteraan sosialnya. Sementara menurut Loekman intervensi pada masyarakat menjadi satu bentuk kegiatan untuk mewujudkan masyarakat yang partisipatif pada setiap kebijakan dan program yang ada. Sedangkan menurut Korten (2002), pelaksanaan intervensi pada masyarakat merupakan upaya dalam menggalang kemandirian masyarakat melalui penguatan kemandirian lokal. Kondisi partisipasi masyarakat inilah yang sekiranya terbangun dalam kegiatan kebencanaan yang dilakukan oleh TAGANA. Oleh karena itulah kegiatan yang dilakukan TAGANA dapat dilakukan berkat kerjasama dan partisipasi yang dilakukan oleh masyarakat. Terkait dengan partisipasi 
masyarakat, hal ini seperti yang dikemukakan oleh Midgley (2005), bahwa pentingnya partisipasi masyarakat sebagai pendukung dalam kegiatan pengembangan masyarakat (intervensi).

\section{b. Tenaga Profesional}

Berdasarkan temuan data di lapangan, bahwa pengetahuan dan skill tentang penanganan bencana menjadi sebuah kebutuhan mendasar dalam mengurangi resiko saat terjadi bencana. Dalam hal ini terlihat dari pelaksanaan kegiatan kebencanaan yang dilakukan oleh TAGANA. Dimana pengetahuan dan keterampilan yang dimilikinya, dapat dijalankan dan disosialisasikan kembali dengan baik kepada masyarakat. Terkait dengan tenaga profesional, menurut Midgley (2005) program pembangunan masyarakat bergantung pada tenaga profesional yang terlatih untuk memobilisasi partisipasi lokal, mengorganisir aktifitas dan menghubungkan masyarakat dengan sumber eksternal. Para profesional bisa dari badan pengembangan masyarakat yang dipekerjakan dan bisa juga menggunakan tenaga lokal yang sudah terlatih.

Sementara itu mengenai masalah kualitas kemampuan SDM mengenai kebencanaan, menurut Coppola (2011) ini berkaitan dengan kemampuan pengetahuan dan keterampilan dibidang kebencanaan, harus dimiliki dalam melakukan manajemen kebencanaan. Dengan adanya kualitas SDM, maka manajemen kebencanaan pun akan menjadi berkualitas. Hal ini karena antar elemen masing-masing memiliki kapasitas dibidang manajemen kebencanaan. Hal ini juga sebagaimana yang dikemukakan Nurjanah dkk. (2012), “dalam manajemen bencana setiap SDM harus memiliki kemampuan mengenai kebencanaan dan menyamakan persepsi tentang manajemen bencana".

Sementara, faktor penghambat yang dapat mengganggu pelaksanaan model intervensi komunitas TAGANA dalam penanggulangan bencana alam di Kabupaten Deli Serdang, yaitu sebagai berikut:

\section{a. Faktor Presdiposisi}

Berdasarkan temuan data di lapangan, dalam pelaksanaan kegiatan TAGANA masih terjadi ketidak pahaman pengurus dalam menjalankan tugasnya yang sesuai dengan jabatannya dalam struktur organisasi. Kondisi tersebut terjadi karena permasalahan yang berasal dari kepribadian anggota TAGANA di dalamnya. Kondisi tersebut merupakan bagian dari faktor presdiposisi. Menurut Watson (dalam Adi, 2008), terdapat berbagai macam hambatan yang dapat menghambat perubahan atau perkembangan dalam pemberdayaan melalui intervensi dari kepribadian individu, salah satunya adalah keterbatasan faktor 
predisposisi. Faktor predisposisi adalah hal-hal yang muncul sebelum perilaku terjadi dan memberikan motivasi atau dasar rasional bagi perilaku manusia, seperti pengetahuan, kepercayaan, nilai, sikap, dan pendapat masyarakat sasaran..

b. Ketergantungan

Dalam menjalankan peran dan fungsinya terkadang TAGANA mendapatkan kendala. Dimana kendala yang sangat dirasakan oleh TAGANA berkaitan dengan masalah dana. Sebab dalam berbagai kegiatan, TAGANA bergantung dengan dana untuk mendanai kegiatan yang dilakukan. Dengan adanya ketergantungan dana, dirasakan oleh TAGANA menghambat kinerja mereka dalam berbagai kegiatan kebencanaan. Padahal harusnya dana yang mumpuni, menjadi faktor pendukung dalam pelaksanaan kegiatan kebencanaan. Namun justru sebaliknya, dana menjadi kendala bagi pelaksanaan kegiatan penanggungalan kebencanaan yang dilakukan oleh TAGANA. Hal ini seperti yang dikemukakan oleh Nurjanah dkk. (2012), bahwa tanpa adanya sumber daya finansial akan menghambat proses pelaksanaan kegiatan manajemen bencana. Sedangkan menurut Hill (2009), kemampuan finansial merupakan faktor penting untuk mewujudkan tujuan kegiatan. Tanpa adanya finansial, maka suatu kegiatan tidak akan berjalan secara maksimal. Ketergantungan dana merupakan kendala dalam menjalankan kegiatan. Hal ini seperti yang dikemukakan Watson, jika dalam suatu kelompok terlalu mengalami ketergantungan terhadap orang lain (dalam hal ini masalah bantuan dana) maka proses pemandirian masyarakat tersebut dapat menjadi lebih lama (Adi, 2008).

\section{Keberhasilan TAGANA dalam Intervensi Komunitas}

Berdasarkan temuan di lapangan dan hasil analisis, maka untuk mempermudah dalam memahami tingkat keberhasilan intervensi komunitas yang dilakukan oleh TAGANA Kabupaten Deli Serdang bisa di lihat dari tabel berikut:

Tabel 3 Perbandingan Keberhasilan TAGANA dalam Intervensi Komunitas

\begin{tabular}{|c|c|c|c|c|}
\hline No & Indikator & $\begin{array}{r}\text { Sebelum Ada } \\
\text { dari T }\end{array}$ & nter & $\begin{array}{l}\text { Sesudah Adanya } \\
\text { Intervensi dari } \\
\text { TAGANA }\end{array}$ \\
\hline 1 & $\begin{array}{l}\text { Pengetahuan } \\
\text { masyarakat dalam } \\
\text { penanggulangan } \\
\text { bencana. }\end{array}$ & $\begin{array}{l}\text { Pengetahuan } \\
\text { terhadap } \\
\text { penanggulangan } \\
\text { terbilang minim. }\end{array}$ & $\begin{array}{r}\text { masyarakat } \\
\text { proses } \\
\text { bencana }\end{array}$ & $\begin{array}{l}\text { Pengetahuan masyarakat } \\
\text { terhadap proses } \\
\text { penanggulangan bencana } \\
\text { mulai meningkat. }\end{array}$ \\
\hline 2 & $\begin{array}{l}\text { Keterampilan } \\
\text { masyarakat dalam } \\
\text { penanggulangan } \\
\text { bencana. }\end{array}$ & $\begin{array}{l}\text { Keterampilan } \\
\text { terhadap } \\
\text { penanggulangan } \\
\text { terbilang minim. }\end{array}$ & $\begin{array}{r}\text { masyarakat } \\
\text { proses } \\
\text { bencana }\end{array}$ & $\begin{array}{l}\text { Keterampilan masyarakat } \\
\text { terhadap proses } \\
\text { penanggulangan bencana } \\
\text { mulai meningkat. }\end{array}$ \\
\hline
\end{tabular}




\begin{tabular}{|c|l|lr|lr|}
\hline 3 & $\begin{array}{l}\text { Tingkat partisipasi } \\
\text { masyarakat dalam } \\
\text { kegiatan } \\
\text { penanggulangan } \\
\text { bencana. }\end{array}$ & $\begin{array}{l}\text { Masih rendahnya tingkat } \\
\text { partisipasi masyarakat } \\
\text { terhadap kegiatan } \\
\text { penanggulangan bencana. }\end{array}$ & $\begin{array}{l}\text { Mulai tingginya tingkat } \\
\text { partisipasi rasyarakat } \\
\text { terhadap kegiatan } \\
\text { penanggulangan bencana. }\end{array}$ \\
\hline 4 & $\begin{array}{l}\text { Dampak resiko dari } \\
\text { bencana. }\end{array}$ & $\begin{array}{l}\text { Tingginya dampak resiko } \\
\text { yang terjadi dari setiap } \\
\text { bencana yang terjadi, } \\
\text { khususnya dalam aspek } \\
\text { kerugian materi. }\end{array}$ & $\begin{array}{l}\text { Berkurangnya dampak } \\
\text { resiko yang terjadi dari } \\
\text { setiap bencana yang } \\
\text { terjadi. }\end{array}$ \\
\hline
\end{tabular}

Sumber: Diolah Berdasarkan Temuan Peneliti, 2015.

\section{KESIMPULAN}

Model intervensi komunitas yang dirumuskan oleh Rothman dibagi menjadi tiga model, yaitu: (1) Model A berupa Pengembangan Masyarakat Loka; (2) Model A berupa Kebijakan Sosial/Perencanan Sosial; dan (3) Model C berupa Aksi Sosial. Terkait dengan ketiga model intervensi komunitas tersebut, hasil penelitian menunjukkan bentuk intervensi komunitas model A yaitu intervensi berupa pengembangan masyarakat lokal, dalam hal ini mengenai penanggulangan bencana yang dilakukan TAGANA Kabupaten Deli Serdang kepada masyarakat di Kabupaten Deli Serdang. Dalam kegiataan intervensi komunitas yang dilakukan oleh TAGANA dalam penanggulangan bencana alam di Kabupaten Deli Serdang ada beberapa faktor pendukung yang membantu keberhasilan pelaksanaan intervensi, seperti adanya partisipasi masyarakat dan tenaga profesional. Namun fakta di lapangan juga menunjukan bahwa TAGANA menghadapi faktor penghambat pelaksanaan intervensi, seperti faktor predisposisi dan ketergantungan masalah dana.

\section{DAFTAR PUSTAKA}

Adi, I. R. (2008). Intervensi Komunitas Pengembangan Masyarakat Sebagai Upaya Pemberdayaan Masyarakat. Jakarta: Rajawali.

Alcántara-Ayala, I. (2002). Geomorphology, natural hazards, vulnerability and prevention of natural disasters in developing countries. Geomorphology, 47(2-4), 107-124.

Benson, C., \& Clay, E. J. (2000). Developing countries and the economic impacts of natural disasters. Managing disaster risk in emerging economies, 11-21.

Caruso, G. D. (2017). The legacy of natural disasters: The intergenerational impact of 100 years of disasters in Latin America. Journal of Development Economics, 127, 209233.

Christy, C., \& Sahrani, R. (2017). Hubungan Place Attachment dengan perilaku Prososial Relawan Sosial. Provitae: Jurnal Psikologi Pendidikan, 8(2). 
Coppola, D. P. (2011). Introduction to international disaster management. USA: Elsevier.

Crespo Cuaresma, J., Hlouskova, J., \& Obersteiner, M. (2008). Natural disasters as creative destruction? Evidence from developing countries. Economic Inquiry, 46(2), 214-226.

Data Bencana di Kabupaten Deli Serdang. Tim Tagana Deli Serdang, 2013.

Davis, J. (2017). Fertility after natural disaster: Hurricane Mitch in Nicaragua. Population and environment, 38(4), 448-464.

Delaney, P. L., \& Shrader, E. (2000). Gender and post-disaster reconstruction: The case of Hurricane Mitch in Honduras and Nicaragua. Decision review draft. Washington, DC: LCSPG/LAC Gender Team, The World Bank.

Deli Serdang Dalam Angka. Badan Pusat Statistik Kabupaten Deli Serdang, 2012.

Ferrier, B. A., \& Spickett, J. T. (2007). Natural disasters in developing countries: an environmental health perspective. Asia Pacific Journal of Public Health, 19(1_suppl), $18-24$.

Hidayati, D. (2008). Kesiapsiagaan Masyarakat: Paradigma Baru Pengelolaan Bencana Alam. Jurnal Kependudukan Indonesia, 3(1), 69-84.

Hikmat, H. (2004). Strategi pemberdayaan masyarakat. Bandung: Humaniora

Hill, A. (2009). Strategic Financial Management: Exercise Book. Ventus Publishing.

ITB. (2009). Mengelola Risiko Bencana di Negara Maritim Indonesia. Bandung: Lembaga Penelitian dan Pengabdian Masyarakat ITB.

Kementerian Sosial Republik Indonesia. (2006). Taruna Siaga Bencana (Tagana) Sebagai Gugus Tugas Penanggulangan Bencana Berbasis Komunitas. Jakarta: Dirjen Bantuan dan Jaminan Sosial Direktorat Bantuan Sosial Korban Bencana Sosial Kementerian Sosial.

Korten, C. D. (2002). Menuju Abad Ke-21, Tindakan Sukarela dan Agenda

Loekman, S. (1995). Menuju Masyarakat Partisipatif. Yogyakarta: Kanisius

Midgley, J. (2005). Pembangunan Sosial: Perspektif Pembangunan dalam Kesejahteraan Sosial. Jakarta: Ditperta Depag RI.

Neuman, W. L. (2006). Social research methode: qualitative and quantitative approach (Sixth Edition).Needham Heights. MA: Allyn \& Bacon.

Nurjanah, dkk. (2012). Manajemen Bencana. Bandung: Alfabeta.

Peraturan Menteri Sosial Republik Indonesia Nomor 28 Tahun 2012 Tentang Pedoman Umum Taruna Siaga Bencana.

Roper, W. E. (2001). Hurricane Mitch Reconstruction Partnerships and Progress. NIST SPECIAL PUBLICATION SP, 513-530.

Rubin, A., \& Babbie, E. R. (2008). Research Methods for Social Work. USA: Thomson Brooks/Cole.

Sadisun, I. A. (2004). Manajemen bencana: Strategi hidup di wilayah berpotensi bencana. Keynote Speaker.

Strobl, E. (2012). The economic growth impact of natural disasters in developing countries: Evidence from hurricane strikes in the Central American and Caribbean regions. Journal of Development Economics, 97(1), 130-141. 
Suharto, E. (2012). Analisis kebijakan publik: panduan praktis mengkaji masalah dan kebijakan sosial. Bandung: Alfabeta.

Sunarti, E (2009). Evaluasi penanggulangan bencana di Indonesia (lesson learned 20062007). Bogor: Pusat Studi Bencana Lembaga Penelitian dan Pengabdian kepada Masyarakat Institut Pertanian Bogor.

Syamsuddin, A. B. (2019). Peran Anggota Tagana Terhadap Penanggulangan Bencana di Fakultas Dakwah Dan Komunikasi Uin Alauddin Kabupaten Gowa. Jurnal Mimbar Kesejahteraan Sosial, 1(1).

Tondobala, L. (2012). Pemahaman tentang kawasan rawan bencana dan tinjauan terhadap kebijakan dan peraturan terkait. $S A B U A, 3(1)$.

Toya, H., \& Skidmore, M. (2007). Economic Development and the Impacts of Natural Disasters. Economics letters, 94(1), 20-25.

Tselios, V., \& Tompkins, E. L. (2019). What Causes Nations to Recover From Disasters? An Inquiry into the Role of Wealth, Income Inequality, and Social Welfare Provisioning. International journal of disaster risk reduction, 33, 162-180.

Undang-Undang Nomor 11 tahun 2009 Tentang Kesejahteraan Sosial.

Undang-Undang Nomor 24 Tahun 2007 tentang Penanggulangan Bencana.

Widianto, E. (2019). Implementasi Pelaksanaan Pelatihan Kesiapsiaagan Dalam Menghadapi Bencana Bagi Generasi Muda. Jurnal Graha Pengabdian, 1(2), 51-61.

Wulandari, R. (2017). Analisis Kesiapan Pemerintah Daerah Dalam Penanganan Penyandang Disabilitas Menghadapi Bencana Gempa Bumi. Jurnal Manajemen Bencana (JMB), 3(1). 